\title{
DIFERENCIAÇÃO FLORAL DO ABACAXIZEIRO cv. SNG-3 EM FUNÇÃO DA IDADE DA PLANTA E DA APLICAÇÃO DO CARBURETO DE CÁLCIO ${ }^{1}$
}

\author{
TARCÍSIO MARCOS DE SOUZA GONDIM² \& FRANCISCO FELISMINO DE AZEVEDO³
}

\begin{abstract}
RESUMO - Objetivando determinar a influência de carbureto de cálcio na diferenciação floral do abacaxizeiro, cv. SNG-3, nas condições de Rio Branco-AC, foi realizado um experimento, no período de 05/1999 a 12/2000, utilizando-se de mudas tipo filhote selecionadas por peso (250-300 gramas), plantadas em 12 de maio de 1999. O delineamento experimental foi o de blocos casualizados em esquema fatorial, sendo combinados os fatores idades de indução ( $8 ; 10$ e 12 meses após o plantio) e horários de aplicação manhã (7h $30 \pm 20$ ') e tarde (15h $30 \pm 20^{\prime}$ ), além da testemunha (indução natural). A indução foi feita com carbureto de cálcio, em pedras com peso médio de $0,8 \mathrm{~g} /$ planta em única aplicação. O carbureto de cálcio estimulou a floração do abacaxizeiro, com melhor resposta, quando aplicado a partir dos 10 meses do plantio, antecipando a colheita em 100 dias. A indução floral mais tardia, aos 10 e 12 meses de idade, favorece a produção de frutos mais pesados, menos ácidos e com maior teor de sólidos solúveis, com ciclos de 475 dias a 558 dias, respectivamente. O horário de aplicação do carbureto de cálcio, pela manhã, influenciou a altura e a floração das plantas, sem alterar a qualidade (peso, acidez e SST) dos frutos de abacaxi cv. SNG-3.
\end{abstract}

Termos para indexação: Ananas comosus, horário de aplicação, peso de fruto, sólidos solúveis.

\section{FLORAL DIFFERENTIATION OF THE PINEAPPLE cv. SNG-3 IN FUNCTION OF THE PLANT AGE AND OF THE CALCIUM CARBIDE APPLICATION}

\begin{abstract}
Aiming to determine the influence of calcium carbide in the floral differentiation of the pineapple, cv. SNG-3, in the conditions of Rio Branco, AC, Brazil, an experiment was carried out in the period of 05/1999 to 12/2000, using seedlings selected by weight (250-300 g), planted on May 12, 1999. The experimental design was a complete randomized block in factorial, with the factors induction ages (eighth, tenth and twelfth month after the planting) and the application time morning $\left(07: 30 \mathrm{~h} \pm 20^{\prime}\right)$ and in the afternoon $\left(15: 30 \mathrm{~h} \pm 20^{\prime}\right)$, besides natural induction. The induction was done using calcium carbide stones, weighting $0.8 \mathrm{~g} / \mathrm{plant}$ in a single application. The calcium carbide stimulated flowering of the pineapple cv. SNG-3, with better efficiency when accomplished after the ten moths of the planting, advancing the crop in 100 days. The later floral induction dates, 10 and 12 months of age, favored the production of heavier fruits, less acids and with higher content of total soluble solids, with cycles of 475 days and 558 days, respectively. The application in the morning of the calcium carbide influenced the height and the flowering of the plants, without altering the quality (weight, acidity and content of total soluble solids) of the fruits of pineapple cv. SNG-3.
\end{abstract}

Index terms: Ananas comosus, application time, fruit weight, soluble solids.

\section{INTRODUÇÃO}

O abacaxizeiro (Ananas comosus ( L. ) Merril) é cultivado na maioria dos países de clima tropical e subtropical. No Brasil, são encontrados plantios comerciais em todo o território, destacando-se os Estados de Minas Gerais, Pará, Paraíba e Bahia que, em 1999, contribuíram com 70,26\% da produção nacional e 61,78\% da área colhida do País (IBGE, 2001). No Acre, com 157 ha colhidos em 1999 (0,28\% da área nacional), o cultivo do abacaxizeiro vem assumindo grande importância social e econômica. Os plantios baseiam-se nas cultivares locais 'Cabeça-de-onça', 'Quinari', 'Rio Branco' e 'SNG-3' (Ritzinger, 1992; Donadio, 2000).

A escassez de conhecimentos sobre o comportamento dessas cultivares no âmbito do mais racional e econômico manejo é característica limitante do cultivo do abacaxi no Acre, principalmente na distribuição da produção de frutos ao longo do ano.
Segundo Cunha et al. (1993), quando a cultura é submetida a tratos culturais adequados, pode produzir comercialmente durante todo o ano, ou então fora da época normal da safra. Os autores mencionam ainda que a época de plantio, o tamanho da muda e a idade da planta, por ocasião do tratamento de indução floral, são fatores que, combinados convenientemente, podem proporcionar adequado escalonamento da produção, melhor distribuição das práticas culturais e da mão-de-obra na propriedade e redução das perdas dos frutos por doenças e pragas, com conseqüente aumento da produtividade e dos lucros da cultura.

Cunha (1999) menciona que a hora de aplicação do indutor de florescimento é muito importante, devendo ser feita preferencialmente à noite (entre $20 \mathrm{~h} \mathrm{e} 5 \mathrm{~h}$ ), ou em dias nublados. O horário noturno, portanto, implica maior dificuldade operacional, além de inconveniente para os agricultores, que não têm estruturas e hábitos para os trabalhos noturnos.

O conhecimento da indução floral do abacaxizeiro tor-

1 (Trabalho 134/2001). Recebido: 23/08/2001. Aceito para publicação: 04/06/2002.

2 Eng ${ }^{\underline{A}}$ Agro ${ }^{\circ}$, M.Sc., Pesquisador. Embrapa Algodão, Caixa Postal 174, CEP 58107-720, Campina Grande, PB. Tel.:(83) 341-3608; (88) 532-3031. Email: tarcisio@cnpa.embrapa.br.

3 Eng ${ }^{\circ}$ Agr ${ }^{\circ}$, Assistente de Pesquisa. Embrapa Acre, Caixa Postal 321, CEP 69908-970, Rio Branco, AC.

Rev. Bras. Frutic., Jaboticabal - SP, v. 24, n. 2, p. 420-425, agosto 2002 
nou viável o cultivo racional desta espécie (Ferrão, 1999). Segundo Sampaio et al. (1997), a diferenciação floral natural pode contribuir para a diminuição do rendimento quando ocorre de maneira desuniforme, pois determina variações na época de maturação dos frutos, dificulta os tratos fitossanitários e a colheita. Em contrapartida, a interferência no processo de diferenciação floral natural, por meio de indutores do florescimento, a exemplo do carbureto de cálcio (precursor do acetileno), com eficiência na indução floral superior a $90 \%$, possibilita a colheita de frutos com padrão comercial em meses com maiores índices estacionais de preço. Bezerra et al. (1978), em Pernambuco, realizaram indução floral do abacaxizeiro cv. Smooth Cayenne aos 6; 7; 8; 9; 10 e 11 meses de idade e concluíram que, com induções precoces, tornase possível reduzir o ciclo da cultura e produzir na entressafra. Choairy \& Fernandes (1984), em condições da Paraíba, realizaram induções da cv. Smooth Cayenne aos 8; 10; 12 e 14 meses após o plantio e observaram que o peso médio de frutos com e sem coroa depende da idade com que as plantas são induzidas ao florescimento, sendo maior nas induções mais tardias.

A cultivar de abacaxi cv. SNG-3, que apresenta padrão semelhante ao da cv. Smooth Cayenne (Ritzinger, 1992), e por ser bem adaptada às condições edafoclimáticas do Estado do Acre, salienta-se à tolerância à acidez e à falta de água no período seco. Ritzinger (1991) observou que o florescimento natural da cv. SNG3 se iniciou aos 15 meses do plantio e o período compreendido entre o surgimento da inflorescência e a colheita do fruto foi de 118 dias, totalizando 568 dias, o que pode ser muito longo.

Este trabalho teve como objetivo avaliar a influência do horário de aplicação do carbureto de cálcio e da idade das plantas na diferenciação floral e produção do abacaxizeiro cv. SNG-3 nas condições de Rio Branco-Acre.

\section{MATERIAL E MÉTODOS}

Este trabalho foi conduzido no Campo Experimental da Embrapa Acre, em Rio Branco-AC, com coordenadas de S $10^{\circ} 01$ '30', e W 67\%42' $18^{\prime}$ ', e altitude de aproximadamente $160 \mathrm{~m}$. Utilizou-se a cultivar de abacaxi cv. SNG-3, que apresenta padrão semelhante ao da cv. Smooth Cayenne (Ritzinger, 1991). O clima é quente e úmido, com estações seca e úmida bem definidas. A distribuição mensal de pluviosidade, temperatura e umidade relativa do ar, durante o período do ensaio, encontra-se na Tabela 1. O solo é classificado como Argissolo Vermelho de topografia plana, apresentando as seguintes características químicas: $\mathrm{pH}$ (água) $=5,0 ; \mathrm{P}=1,0 \mathrm{mg} \mathrm{dm}^{-3} ; \mathrm{K}=0,10 \mathrm{cmol}_{\mathrm{c}} \mathrm{dm}^{-3} ; \mathrm{Ca}+\mathrm{Mg}=3,20$ $\mathrm{cmol}_{\mathrm{c}} \mathrm{dm}^{-3} ; \mathrm{Al}=0,20 \mathrm{cmol}_{\mathrm{c}} \mathrm{kg}^{-1} ; \mathrm{e} \mathrm{C}=0,53 \mathrm{~g} \mathrm{~kg}^{-1}$.

O plantio foi realizado no dia 12 de maio de 1999, utilizando mudas tipo filhote selecionadas por peso (250 a 300 gramas), em covas no espaçamento $0,90 \mathrm{~m}$ x $0,40 \mathrm{~m}$, em fileiras simples. Os tratos culturais e adubações seguiram as recomendações de Choairy (1992). Durante a condução do ensaio, foram feitas quatro pulverizações com dois gramas por litro do inseticida Carbaryl, para controle do percevejo-do-abacaxizeiro (Thlastocoris laetus Mayr, 1866).

O delineamento experimental foi em blocos casualizados, com quatro repetições, em esquema fatorial, sendo combinados três idades de indução (aos 8, aos 10 e aos 12 meses após o plantio) e dois horários de aplicação, manhã (07h 30 土 20’) e tarde (15h $30 \pm 20$ '), além da testemunha (indução natural versus carbureto), totalizando sete tratamentos. $\mathrm{O}$ delineamento pode ser representado de acordo com a seguinte matriz [ $(3 \times 2)+1]$. As parcelas foram constituídas por 40 plantas distribuídas em quatro filas de 10 plantas, considerando-se úteis as 20 plantas das duas filas centrais, descartando-se as laterais, que compuseram a bordadura. A comparação das médias foi feita pelo teste de Tukey.

O estímulo da indução floral foi feito com carbureto de cálcio comercial, na forma sólida, em pedras com peso médio de 0,8 g/planta em única aplicação, nos horários da manhã ou tarde, conforme o respectivo tratamento, com auxílio de um funil de tubo prolongado, colocado no centro da roseta foliar.

As avaliações das plantas e dos frutos foram realizadas a partir da colheita, procedida quando os frutos apresentavam cerca de $30 \%$ a $50 \%$ da casca com coloração amarelada. Avaliaram-se os seguintes caracteres: altura das plantas, determinada da superfície do solo até a extremidade terminal do pedúnculo (base do fruto); diâmetro do pedúnculo, aferido no terço mediano com auxílio de um paquímetro digital; número de filhotes; número de rebentos (mudas tipo filhote-rebentão e rebentão); porcentagem de floração (emissão de inflorescências observadas aos 60 dias após o tratamento de indução, ou na colheita, no caso da indução natural); índices físicos da fruta: peso com e sem coroa; peso da coroa; índices químicos: acidez total titulável do suco (\% de ácido cítrico); sólidos solúveis totais (SST) por meio de refratômetro manual, com posterior correção dos valores observados para temperatura ambiente, de acordo com Pregnolatto \& Pregnolatto (1985); e, por último, a relação SST/ acidez.

As análises estatísticas foram realizadas utilizando o Software Científico/Núcleo Tecnológico para Informática Agropecuária - SOC/NTIA (Paniago, 1987).

\section{RESULTADOS E DISCUSSÃO}

Houve diferenças significativas na altura (ALT), no diâmetro de pedúnculo (DP), número de filhotes (NF), número de rebentões (NR), porcentagem de plantas floradas (PPF), peso da fruta com coroa (PFCC) e sem coroa (PFSC), peso da coroa (PC), acidez titulável (AT), sólidos solúveis totais (SST) e relação SST/ AT das plantas induzidas artificialmente, em relação às idades de indução (Tabelas 2 e 3). Quanto ao horário de aplicação do indutor floral, houve diferença significativa apenas para a altura e porcentagem de plantas floradas. Para todos os caracteres analisados, a interação entre os fatores idade de indução e horário de aplicação do carbureto de cálcio foi não significativa, mostrando que a resposta do abacaxizeiro cv. SNG-3 à idade de indução independe do horário em que o mesmo é aplicado. Houve diferença significativa do tratamento adicional (indução natural versus carbureto de cálcio) para os caracteres ALT, DP, NF, NR, PPF, PFCC, PFSC e SST. Para o PC, AC e SST/AC, não houve diferença significativa (Tabelas 2 e 3 ).

\section{Idade de indução}

Nas Tabelas 4 e 5, observa-se a comparação das médias, permitindo a análise dos efeitos isolados de cada fator. A resposta das plantas à idade em que foram induzidas ao 
florescimento mostrou altura maior para aquelas tratadas com carbureto de cálcio aos 12 meses do plantio e menor para as induzidas aos 10 meses, que superaram as estimuladas artificialmente aos 8 meses do plantio (Tabela 4). Este resultado está de acordo com Ferrão (1999), que menciona ser a influência do carbureto de cálcio responsável pela mudança da fase vegetativa para a reprodutiva, o que resultou em plantas de porte variando de acordo com sua idade de indução. Comportamento semelhante foi verificado para o DP e número de mudas tipo filhote, o que pode ser atribuído à maior idade e desenvolvimento vegetativo dos abacaxizeiros quando ocorreu o estímulo à floração. Esses resultados foram semelhantes aos obtidos por Melo (1993). A produção de mudas tipo rebentão (filhote-rebentão e rebentão) não foi alterada pela idade de indução (Tabela 4). Choairy et al. (1994a) verificaram que, para a cv. Smooth Cayenne, a produção de rebentos/ha foi significativamente maior com a indução floral realizada aos 12 meses do plantio.

Observa-se ainda, na Tabela 4, menor porcentagem de floração $(48,75 \%)$ para as plantas induzidas aos 8 meses que para as tratadas aos $10(83,12 \%)$ e 12 meses $(93,12 \%)$, correspondendo a um aumento médio superior $80 \%$, atribuindose ao menor estádio vegetativo apresentado pelas plantas aos 8 meses do plantio. Segundo Cunha (1999), a resposta ao tratamento de indução artificial varia de acordo com o vigor e taxa de crescimento da planta.

A indução aos 8 meses reduziu o ciclo do abacaxizeiro de 575 dias (plantas que não receberam carbureto de cálcio) para 398 dias (Tabela 5). No entanto, o PFCC e PFSC foram menores que o dos frutos produzidos aos 10 meses (ciclo de 475 dias) e 12 meses (ciclo de 558 dias), atribuindo-se ao desenvolvimento vegetativo das plantas no momento da indução da floração. A colheita aos 475 e 558 dias do plantio antecipa a produção de frutos da cv. SNG-3 em 100 dias (3,3 meses) e 17 dias, respectivamente, em relação às plantas estimuladas ao natural. Salienta-se que, mesmo com pequena diferença no ciclo das plantas induzidas aos 12 meses, há vantagens no uso da indução devido à melhor uniformidade na floração e maturação dos frutos (Reinhardt \& Cunha, 2000). Na indução aos 12 meses do plantio, houve aumento no ciclo da cultura de 83 dias (558-475), em relação à indução aos 10 meses, proporcionando aumento do ciclo de 23 dias, devido, provavelmente, à maior regularidade das condições climáticas (precipitação, temperatura, umidade, nebulosidade, luminosidade) ocorrida no período de crescimento e maturação dos frutos das plantas induzidas aos 12 meses. As plantas estimuladas aos 10 e 12 meses não apresentaram diferença significativa entre si. Os resultados comprovam os de outros autores que obtiveram frutos de abacaxi mais pesados quando as plantas foram induzidas ao florescimento mais tardiamente (Vieira et al., 1983; Choairy \& Fernandes, 1984; Cunha et al., 1993; Melo, 1993; Choairy et al. 1994a, 1994b).

O maior peso dos frutos sem coroa apresentados pelas plantas induzidas à floração aos 10 e 12 meses após o plantio, com 872 g e $908 \mathrm{~g}$, respectivamente, em relação àquelas tratadas aos 8 meses (698 g), enquadra-se, segundo Coelho \& Cunha (1982), nos padrões de peso de 700 a $1.500 \mathrm{~g}$ destinados ao consumo in natura.

Plantas induzidas pelo estímulo natural (cerca de 13 meses do plantio) produziram frutos maiores (peso médio de $1.040 \mathrm{~g}$ ) que as induzidas aos 8; 10 e 12 meses (frutos com peso médio de 998 g) (Tabela 5), devido ao menor desenvolvimento vegetativo, com conseqüente menor quantidade de reservas acumuladas destas plantas, no momento da indução da floração.

Quanto ao PC, observou-se que as plantas induzidas aos 8 meses produziram coroas menos pesadas (154 g) (Tabela 5). Quando induzidas aos 10 meses, o peso da coroa (192 g) foi maior que o das induzidas aos 12 meses $(171 \mathrm{~g})$. Estes resultados estão de acordo com os observados para a cv. Pérola, por Melo (1993), e por Manica et al. (1994), para a cv. Smooth Cayenne, que obtiveram maiores pesos de coroas nas frutas cujas plantas foram induzidas mais precocemente. Não houve diferença entre PC das plantas induzidas em relação às estimuladas ao natural (Tabela 5).

As plantas induzidas com idade mais avançada (10 e 12 meses do plantio) produziram frutos com menor acidez e mais ricos em sólidos solúveis totais (Tabela 5). Comportamento semelhante da influência da idade de indução floral do abacaxizeiro sobre a qualidade do fruto também foi observado em outros trabalhos com a cultivar 'Smooth Cayenne', por Choairy \& Fernandes (1984) e Choairy et al. (1994a), e com a cultivar 'Pérola' (Choairy et al., 1994b).

TABELA 1 - Distribuição de precipitação, temperatura e umidade (médias mensais) observadas durante a condução do ensaio de indução floral do abacaxizeiro cv. SNG-3. Rio Branco, AC.

\begin{tabular}{|c|c|c|c|c|c|c|}
\hline \multirow{2}{*}{ MESES } & \multicolumn{2}{|c|}{ Precipitação (m m) } & \multicolumn{2}{|c|}{ Temperatura $\left({ }^{\circ} \mathrm{C}\right)$} & \multicolumn{2}{|c|}{ Umidade $(\%)$} \\
\hline & 1999 & 2000 & 1999 & 2000 & 1999 & 2000 \\
\hline Janeiro & -- & 188,80 & -- & 25,2 & -- & 90,4 \\
\hline Fevereiro & -- & 332,10 & -- & 24,9 & -- & 91,6 \\
\hline Março & -- & 151,20 & -- & 25,1 & -- & 81,6 \\
\hline Abril & -- & 244,40 & -- & 24,7 & -- & 94,9 \\
\hline Maio & 14,3 & 60,20 & 26,1 & 24,7 & 82,5 & 87,4 \\
\hline Junho & 18,6 & 8,90 & 25,5 & 23,8 & 83,0 & 88,5 \\
\hline Julho & 20,0 & 54,20 & 25,0 & 22,4 & 84,0 & 78,8 \\
\hline Agosto & 78,0 & 29,40 & 25,7 & 25,3 & 80,2 & 80,1 \\
\hline Setembro & 146,6 & 140,10 & 27,9 & 25,5 & 86,6 & 73,2 \\
\hline Outubro & 153,3 & 168,30 & 27,1 & 25,7 & 73,8 & 84,6 \\
\hline Novembro & 181,7 & 187,20 & 27,0 & 25,8 & 86,8 & 86,8 \\
\hline Dezembro & 324,8 & 211,50 & 27,2 & 25,9 & 88,2 & 85,8 \\
\hline
\end{tabular}

Fonte: Dados fornecidos pelo Instituto do Meio Ambiente do Estado do Acre (Imac) e pela Universidade Federal do Acre (Ufac). 
TABELA 2 - Resumo da análise de variância da altura, diâmetro do pedúnculo, número de filhotes, número de rebentões, porcentagem de plantas floradas em abacaxizeiros cv. SNG-3, em função da idade das plantas e do horário de aplicação do carbureto de cálcio. Rio Branco-AC, 2000.

\begin{tabular}{|c|c|c|c|c|c|c|}
\hline \multirow[b]{2}{*}{ Fonte de Variação } & \multirow[b]{2}{*}{ G L } & \multicolumn{5}{|c|}{ Quadrados Médios } \\
\hline & & $\begin{array}{l}\text { A ltura } \\
(\mathrm{cm})\end{array}$ & $\begin{array}{l}\text { Diâmetro do } \\
\text { pedúnculo } \\
(\mathrm{cm})\end{array}$ & $\begin{array}{l}\mathrm{N}^{\circ} \text { de } \\
\text { filhotes }\end{array}$ & $\begin{array}{c}\mathrm{N}^{\mathrm{o}} \mathrm{de} \\
\text { rebentões }\end{array}$ & $\begin{array}{c}\text { Plantas } \\
\text { floradas } \\
(\%)\end{array}$ \\
\hline Idades de indução (I) & 2 & $375,19 * *$ & $0,40 * *$ & $16,64 * *$ & $0,08 \mathrm{~ns}$ & $4334,38 * *$ \\
\hline Horários de aplicação $(\mathrm{H})$ & 1 & $26,46 * *$ & $0,03 \mathrm{~ns}$ & $0,14 \mathrm{~ns}$ & $0,00 \mathrm{~ns}$ & $1066,67 * *$ \\
\hline Interação I x H & 2 & $1,94 \mathrm{~ns}$ & $0,02 \mathrm{n} \mathrm{s}$ & $0,36 \mathrm{~ns}$ & $0,00 \mathrm{n} \mathrm{s}$ & $232,29 \mathrm{~ns}$ \\
\hline B loco & 3 & $3,79 \mathrm{~ns}$ & $0,01 \mathrm{n} \mathrm{s}$ & $0,20 \mathrm{~ns}$ & $0,04 \mathrm{~ns}$ & $136,11 \mathrm{~ns}$ \\
\hline $\begin{array}{l}\text { Tratamento Adicional } \\
\text { (Indução natural vs carbureto) }\end{array}$ & 1 & $339,43 * *$ & $1,02 * *$ & $12,38 * *$ & $0,25 *$ & $2142,86 * *$ \\
\hline Resíduo & 18 & 1,47 & 0,01 & 0,47 & 0,03 & 102,78 \\
\hline $\mathrm{CV}(\%)$ & & 2,92 & 3,35 & 12,08 & 13,80 & 12,90 \\
\hline
\end{tabular}

** - Significativo a $1 \%$ de probabilidade pelo teste $\mathrm{F}$.

ns - Não significativo.

TABELA 3 - Resumo da análise de variância do peso da fruta com e sem coroa, peso da coroa, acidez titulável total, sólidos solúveis totais e relação SST/acidez em abacaxizeiros cv. SNG-3, em função da idade das plantas e do horário de aplicação do carbureto de cálcio. Rio Branco,-AC, 2000.

\begin{tabular}{lccccccc}
\hline & & \multicolumn{4}{c}{ Quadrados Médios } \\
\cline { 3 - 7 } Fonte de Variação & GL & $\begin{array}{c}\text { Peso da fruta } \\
\text { com coroa }(\mathrm{g})\end{array}$ & $\begin{array}{c}\text { Peso da fruta } \\
\text { sem coroa }(\mathrm{g})\end{array}$ & $\begin{array}{c}\text { Peso da } \\
\text { coroa }(\mathrm{g})\end{array}$ & $\begin{array}{c}\text { Acidez }(\% \\
\text { de ácido } \\
\text { cítrico) }\end{array}$ & $\begin{array}{c}\text { SST } \\
\left({ }^{\circ} \text { Brix }\right)\end{array}$ & $\begin{array}{c}\text { SST/ } \\
\text { Acidez }\end{array}$ \\
\hline Idade de indução (I) & 2 & $129793,82^{* *}$ & $101034,26^{* *}$ & $3006,50^{* *}$ & $0,19 * *$ & $6,64 * *$ & $907,26^{* *}$ \\
Horários de aplicação (H) & 1 & $45431,40 \mathrm{~ns}$ & $38136,45 \mathrm{~ns}$ & $319,01 \mathrm{~ns}$ & $0,00 \mathrm{~ns}$ & $0,00 \mathrm{~ns}$ & $76,08 \mathrm{~ns}$ \\
Interação I x H & 2 & $11121,57 \mathrm{~ns}$ & $15771,22 \mathrm{~ns}$ & $426,89 \mathrm{~ns}$ & $0,01 \mathrm{~ns}$ & $0,54 \mathrm{~ns}$ & $41,89 \mathrm{~ns}$ \\
Bloco & 3 & $25181,99 \mathrm{~ns}$ & $19106,34 \mathrm{~ns}$ & $507,51 *$ & $0,01 \mathrm{~ns}$ & $0,19 \mathrm{~ns}$ & $45,35 \mathrm{~ns}$ \\
$\begin{array}{l}\text { Tratamento Adicional } \\
\text { (Indução natural vs carbureto) }\end{array}$ & 1 & $160210,38^{* *}$ & $158233,96 * *$ & $6,13 \mathrm{~ns}$ & $0,00 \mathrm{~ns}$ & $6,76^{* *}$ & $0,27 \mathrm{~ns}$ \\
Resíduo & 18 & 11028,69 & 11391,36 & 115,09 & 0,01 & 0,40 & 33,16 \\
\hline CV (\%) & & 10,20 & 12,46 & 6,21 & 18,97 & 4,56 & 17,58 \\
\hline
\end{tabular}

*,** - Significativo a $5 \%$ e a $1 \%$ de probabilidade, respectivamente, pelo teste $\mathrm{F}$.

ns - Não significativo.

TABELA 4 - Médias de fatores obtidas para altura, diâmetro do pedúnculo, número de filhotes, número de rebentões e porcentagem de plantas floradas de abacaxizeiros cv. SNG-3, em função da aplicação, da idade das plantas e do horário de aplicação do carbureto de cálcio. Rio Branco-AC, 2000.

\begin{tabular}{|c|c|c|c|c|c|}
\hline \multirow[b]{2}{*}{ Fatores } & \multicolumn{5}{|c|}{ Médias } \\
\hline & $\begin{array}{l}\text { Altura } \\
(\mathrm{cm})\end{array}$ & $\begin{array}{l}\text { Diâmetro do } \\
\text { pedúnculo } \\
(\mathrm{cm})\end{array}$ & $\begin{array}{l}\mathrm{N}^{\mathrm{o}} \mathrm{de} \\
\text { filhotes }\end{array}$ & $\begin{array}{l}\mathrm{N}^{\mathrm{o}} \mathrm{de} \\
\text { rebentões }\end{array}$ & $\begin{array}{c}\text { Plantas } \\
\text { floradas } \\
(\%)\end{array}$ \\
\hline \multicolumn{6}{|l|}{ Idade de indução } \\
\hline 8 meses após o plantio & 33,40 & 2,48 & 3,80 & $1,24 \mathrm{a}$ & $48,75 \quad b$ \\
\hline 10 meses após o plantio & $39,81 \quad b$ & $2,62 \quad b$ & $5,80 \quad \mathrm{~b}$ & $1,12 \mathrm{a}$ & 83,12 a \\
\hline 12 meses após o plantio & $47,08 \mathrm{a}$ & $2,92 \mathrm{a}$ & $6,66 \mathrm{a}$ & $1,32 \mathrm{a}$ & 93,12 a \\
\hline \multicolumn{6}{|l|}{ Horário de aplicação } \\
\hline Manhã $(07 h 30 \pm 20)$ & $39,05 \quad b$ & $2,64 \mathrm{a}$ & $5,47 \mathrm{a}$ & $1,23 \mathrm{a}$ & $81,67 \mathrm{a}$ \\
\hline Tarde $(15 \mathrm{~h} 30 \pm 20)$ & $41,15 \mathrm{a}$ & $2,71 \mathrm{a}$ & $5,32 \mathrm{a}$ & $1,22 \mathrm{a}$ & $68,33 \mathrm{~b}$ \\
\hline Média do fatorial & $40,10 \quad b$ & $2,68 \mathrm{~b}$ & $5,40 \quad b$ & $1,23 \mathrm{~b}$ & $75,00 \quad b$ \\
\hline Média da testemunha & $50,05 \mathrm{a}$ & $3,22 \mathrm{a}$ & $7,30 \mathrm{a}$ & $1,50 \mathrm{a}$ & $100,00 \mathrm{a}$ \\
\hline
\end{tabular}

Ciclo do abacaxizeiro por idade de indução: 8 meses $=398$ dias; 10 meses $=475$ dias; 12 meses $=558$ dias; e testemunha (condições naturais, cerca de 13 meses) $=575$ dias.

Médias seguidas da mesma letra, dentro de cada fator na coluna, não diferem entre si, a 5\% de probabilidade, pelo teste de Tukey. 
TABELA 5 - Médias de fatores obtidas para os caracteres peso da fruta com e sem coroa, peso da coroa, acidez titulável total, sólidos solúveis totais e relação SST/acidez de abacaxizeiros cv. SNG-3, em função da idade das plantas e do horário de aplicação do carbureto de cálcio. Rio Branco-AC, 2000.

\begin{tabular}{|c|c|c|c|c|c|c|}
\hline \multirow[b]{2}{*}{ Fatores } & \multicolumn{6}{|c|}{ Médias } \\
\hline & $\begin{array}{l}\text { Peso da } \\
\text { fruta com } \\
\text { coroa }(\mathrm{g})\end{array}$ & $\begin{array}{l}\text { Peso da } \\
\text { fruta sem } \\
\text { coroa }(g)\end{array}$ & $\begin{array}{c}\text { Peso da } \\
\text { coroa } \\
(\mathrm{g}) \\
\end{array}$ & $\begin{array}{c}\text { Acidez }(\%) \\
\text { de ácido } \\
\text { cítrico) }\end{array}$ & $\begin{array}{c}\mathrm{SST} \\
\left({ }^{\circ} \mathrm{Brix}\right)\end{array}$ & $\begin{array}{c}\mathrm{SST} / \\
\text { Acidez }\end{array}$ \\
\hline \multicolumn{7}{|l|}{ Idade de indução } \\
\hline 8 meses após o plantio & $851,40 \mathrm{~b}$ & $697,82 \quad b$ & 153,58 & $0,64 \mathrm{a}$ & $12,73 \quad b$ & $20,56 \quad b$ \\
\hline 10 meses após o plantio & $1064,29 \mathrm{a}$ & $872,00 \mathrm{a}$ & $192,29 \mathrm{a}$ & 0,35 b & $13,88 \mathrm{a}$ & $40,01 \mathrm{a}$ \\
\hline 12 meses após o plantio & $1079,01 \mathrm{a}$ & $907,94 \mathrm{a}$ & $171,08 \quad b$ & $0,40 \quad b$ & $14,52 \mathrm{a}$ & $37,79 \mathrm{a}$ \\
\hline \multicolumn{7}{|l|}{ Horário de aplicação } \\
\hline Manhã $(07 \mathrm{~h} 30 \pm 20)$ & $954,72 \mathrm{a}$ & $786,06 \mathrm{a}$ & $168,67 \mathrm{a}$ & $0,45 \mathrm{a}$ & $13,70 \mathrm{a}$ & $34,57 \mathrm{a}$ \\
\hline Tarde $(15 \mathrm{~h} 30 \pm 20)$ & $1041,74 \mathrm{a}$ & 865,78 a & $175,96 \mathrm{a}$ & 0,48 a & $13,72 \mathrm{a}$ & $31,01 \mathrm{a}$ \\
\hline Média do fatorial & $998,23 \mathrm{~b}$ & $825,92 \mathrm{~b}$ & $172,31 \mathrm{a}$ & 0,46 a & $13,71 \quad b$ & $32,78 \mathrm{a}$ \\
\hline Média da testemunha & $1214,40 \mathrm{a}$ & $1040,75 \mathrm{a}$ & $173,65 \mathrm{a}$ & $0,47 \mathrm{a}$ & $15,12 \mathrm{a}$ & $32,50 \mathrm{a}$ \\
\hline
\end{tabular}

Ciclo do abacaxizeiro por idade de indução: 8 meses = 398 dias; 10 meses $=475$ dias; 12 meses = 558 dias; e testemunha (condições naturais, cerca de 13 meses) $=575$ dias.

Médias seguidas da mesma letra, dentro de cada fator na coluna, não diferem entre si, a 5\% de probabilidade, pelo teste de Tukey.

\section{Horário de aplicação}

Nas Tabelas 4 e 5, verificou-se que houve influência do horário de aplicação do carbureto de cálcio apenas sobre AP e PPF. As plantas induzidas no horário da tarde apresentaram maior altura $(41 \mathrm{~cm})$ que as induzidas pela manhã $(39 \mathrm{~cm})$.

Em relação ao horário de aplicação do indutor floral, verificou-se que, no horário da manhã, a emissão da inflorescência $(81,67 \%)$ superou a PPF do horário da tarde $(68,33 \%)$ (Tabela 4$)$. A melhor resposta observada no horário matinal pode ser devido à ocorrência de maior absorção do produto aplicado, favorecida pelas condições ambientais do mesmo (horário mais fresco), associadas à melhores atividades fisiológicas da espécie (metabolismo ácido das crassuláceas, abertura de estômatos). De acordo com Py et al., citados por Cunha (1999), é importante que os estômatos permaneçam abertos por três a quatro horas após a aplicação do indutor.

O horário de aplicação do carbureto de cálcio, manhã ou tarde, não influenciou a qualidade dos frutos (peso e índices químicos) (Tabela 5).

\section{CONCLUSÕES}

1. O carbureto de cálcio estimulou a floração do abacaxizeiro cv. SNG-3, com melhor indução, quando a aplicação foi realizada a partir dos 10 meses do plantio, favorecendo a produção de frutos menos ácidos e mais ricos em sólidos solúveis, em ciclos menores.

2. A indução aos 8 meses antecipa a colheita em 177 dias, mas os frutos apresentam baixa qualidade.

3. O horário de aplicação do carbureto de cálcio, pela manhã, influenciou a altura e a floração das plantas, sem alterar a qualidade (peso, acidez e SST) dos frutos de abacaxi cv. SNG-3.

\section{REFERÊNCIAS BIBLIOGRÁFICAS}

BEZERRA, J. E. F.; LEDERMAN, I. L.; AGUIAR, J. A. E.; REIS, O. V. Influência da idade de indução do florescimento e do peso dos filhotes sobre a produção e qualidade do abacaxizeiro
'Cayenne'. Pesquisa Agropecuária Pernambucana, Recife, v. 2, n. 1, p. $45-55,1978$.

CHOAIRY, S. A. O abacaxizeiro: conhecimentos básicos, práticas de cultivo e uso. João Pessoa: EMEPA-PB; Fortaleza: BNB, 1992. 140 p. (EMEPA-PB. Documentos, 16).

CHOAIRY, S. A.; FERNANDES, P. D. Épocas de produção de abacaxizeiro no Estado da Paraíba. Pesquisa Agropecuária Brasileira, Brasília, v. 19, n. 6, p. 729-733, 1984.

CHOAIRY, S. A.; FERNANDES, P. D.; OLIVEIRA, E. F. de. Estudos de época de plantio, peso de muda e idade de indução floral em abacaxi cv. Smooth Cayenne. Pesquisa Agropecuária Brasileira, Brasília, v. 29, n. 1, p. 63-71, 1994a.

CHOAIRY, S. A.; OLIVEIRA, E. F. de; FERNANDES, P. D. Estudos de época de plantio e indução floral em abacaxizeiro Pérola. Pesquisa Agropecuária Brasileira, Brasília, v. 29, n. 1, p. 73-79, $1994 b$.

COELHO, Y. da S.; CUNHA, G. A. P. da. Critérios de avaliação da maturação e qualidade de frutos, com ênfase para citros e abacaxi. Cruz das Almas: EMBRAPA-CNPMF, 1982. 20p. (Circular Técnica, 1).

CUNHA, G. A. P. da. Florescimento e uso de fitorreguladores. In: CUNHA, G. A. P. da.; CABRAL, J. R. dos S.; SOUZA, L. F. de S. O abacaxizeiro: cultivo, agroindústria e economia. Brasília: Embrapa Comunicação para Transferência de Tecnologia, 1999. p. 229-251.

CUNHA, G. A. P. da; REINHARDT, D. H. R. C.; CALDAS, R. C. Efeito da época de plantio, tamanho da muda e idade da planta na indução floral sobre o rendimento do abacaxizeiro 'Pérola' na Bahia. Revista Brasileira de Fruticultura, Cruz das Almas, v. 15 , n. 3, p. 43-50, 1993.

DONADIO, L. C. (Ed.) Novas variedades brasileiras de frutas. Jaboticabal: Sociedade Brasileira de Fruticultura, 2000. 205 p. 
FERRÃO, J. E. M. Ananas comosus (L.) Merr. In: FERRÃO, J. E. M. Fruticultura tropical: espécies com frutos comestíveis. Lisboa: IICT, 1999. v. 1, p. 87-106.

IBGE. Sistema IBGE de recuperação automática-SIDRA. Disponível em: http://www.sidra.ibge.gov.br/bda/tabela/protabl.asp. Acesso em: 28 maio 2001.

MANICA, I.; FIORAVANÇO, J. C.; BARRADAS, C. I. N.; KIST, H.; VIONE, G. F. Indução do florescimento e produção do abacaxizeiro cv. Smooth Cayenne. Pesquisa Agropecuária Brasileira, Brasília, v. 29, n. 1, p. 81-86, 1994.

MELO, G. W. B. de. Época de indução artificial da diferenciação floral do abacaxizeiro 'Pérola' cultivado em área de mata de Roraima. Pesquisa Agropecuária Brasileira, Brasília, v. 28, n. 10, p. 1191-1194, 1993.

PANIAGO, C. S. A.; ANDRADE, D. S. de; TSURUTA, J. H. Software Científico-SOC. Campinas: Embrapa NTIA, 1987. não pág.

PREGNOLATTO, W., PREGNOLATTO, N. P. Frutas e produtos de frutas. In: PREGNOLATTO, W., PREGNOLATTO, N. P. (Coord.). Normas analíticas do Instituto Adolfo Lutz: métodos químicos e físicos para análise de alimentos. 3.ed. São Paulo:
IAL, 1985. v. 1, p. 179-188.

REINHARDT, D. H.; CUNHA, G. A. P. da. Manejo da floração. In: REINHARDT, D. H., SOUZA, L. F. da S.; CABRAL, J. R. S. (Org.) Abacaxi. Produção: aspectos técnicos. Cruz das Almas: Embrapa Mandioca e Fruticultura; Brasília: Embrapa Comunicação para Transferência de Tecnologia, 2000. p. 41-44. (Frutas do Brasil, 7).

RITZINGER, R. Avaliação de duas cultivares de abacaxi em Rio Branco Acre. Revista Brasileira de Fruticultura, Cruz das Almas, v. 13, n. 3, p. 43-48, 1991.

RITZINGER, R. Recomendação de cultivares de abacaxi para o Acre. Rio Branco: EMBRAPA-CPAF/AC, 1992. não pag.

SAMPAIO, A. C.; CUNHA, R. J. P.; CUNHA, A. R. Influência de nitrogênio e de épocas de plantio sobre o crescimento vegetativo e a diferenciação floral natural do abacaxizeiro cv. Smooth Cayenne. Revista Brasileira de Fruticultura, Cruz das Almas, v. 19, n. 1, p. 7-14, 1997.

VIEIRA, A.; GADELHA, R. S. de S.; MALDONADO, J. F. M., SANTOS, A. C. dos. Influência da idade da planta na indução floral sobre a produção do abacaxizeiro. Pesquisa Agropecuária Brasileira, Brasília, v. 18, n. 1, p. 33-35, 1983. 